\title{
Sobre la identidad de "Pío Quinto", un supuesto seudónimo barojiano
}

\author{
About the identity of "Pío Quinto", a supposed barojian pseudonym
}

\author{
José Bernardo San Juan \\ Facultad de Comunicación, Centro Universitario Villanueva, Campus de Mirasierra, \\ C/ Costa Brava, 2, 28034, Madrid, España. Correo electrónico: jbernardos@villanueva.edu
}

\begin{abstract}
Se han atribuido a Pío Baroja los textos escritos en los últimos años del siglo XIX con el seudónimo "Pío Quinto", y como tales se suelen incluir en sus Obras completas. Sin embargo las razones de su atribución no son concluyentes y el autor vasco nunca mencionó haberse servido de ese seudónimo. Pío Quinto firmó 24 artículos, la mayor parte en el semanario Vida Nueva (1898-1900). Se trata de artículos de carácter anticlerical. Los periódicos conservadores denunciaron que tras ese seudónimo estaba el clérigo José Ferrándiz. Ferrándiz se encontraba, en los años de actividad de Pío Quinto, en situación de rebeldía con respecto a la Iglesia. El contenido de los textos es más acorde a la formación y a las circunstancias de Ferrándiz que a las de Baroja. Además, cuando en 1915 Ferrándiz se reincorpore a la Iglesia Católica y firme un texto de arrepentimiento, citará sus artículos de Vida Nueva. Todo parece indicar, entonces, que el seudónimo Pío Quinto no pertenece a Pío Baroja sino al clérigo José Ferrándiz.
\end{abstract}

Palabras clave: seudónimo, Pío Quinto, Pío Baroja, José Ferrándiz, literatura siglo XIX

Scholars have used to attribute to Pío Baroja the articles published under the "nom the plume" Pío Quinto. The fact these articles have been included in the latest edition of his Obras completas only add to the academic belief in Pío Quinto as a pseudonym of Baroja. However, the reasons underlying the attribution are not concluding, and the Basque writer never mentioned this "nom de plume". Pío Quinto wrote 24 articles. The articles themselves are mainly of the antiCatholic genre. This strong stance against clericalism allows us to look for the reply of the conservative press, which was finally to point to the identity hidden beneath the pseudonym: the priest José Ferrándiz, in rebellion against the Church during Pío Quinto's time. The texts themselves seem to be better in line with Ferrándiz's Bildung and circumstances. Also, when Ferrándiz re-enters the Church around 1915, he writes a text showing his repentance, where he quotes his articles as Pío Quinto. Then, all seems to indicate that the pen name Pío Quinto does not belong to Pío Baroja, but to the churchman José Ferrándiz.

Key words: Pen name, Pío Quinto, Pío Baroja, José Ferrándiz, Nineteenth-Century literature 


\section{INTRODUCCIÓN}

Además de los centenares de artículos que Pío Baroja firmó con su nombre, se le han atribuido algunos otros que aparecieron con diversos seudónimos. Se trata, por lo general, de textos que publicó en la prensa del fin de siglo cuando aún era joven y apenas había iniciado su carrera como escritor. A algunos de esos seudónimos después hizo referencia directa o indirecta (es el caso de "Tirteafuera"), pero de otros nunca habló. "Pío Quinto" se encuentra entre los segundos. Recientemente ha quedado demostrado que el pretendido seudónimo barojiano "Pedro Recio de Tirteafuera", usado en la revista Vida Nueva entre 1898 y 1900, pertenecía en realidad al periodista Dionisio Pérez. En el caso de Pío Quinto, la atribución ha sido aceptada por buena parte de la crítica. Sin embargo, si era o no Pío Baroja quien estaba detrás de esa firma, es una cuestión llena de oscuridades.

\section{Los artículos de Pío Quinto}

Con el seudónimo Pío Quinto aparecieron, entre febrero de 1899 y octubre de 1901 , veinticuatro artículos en cinco publicaciones ${ }^{1}$ :

- En El Motín firmó en 1899 dos artículos: "La casa de Pastrana" (1-II-1899: s/p) y "Lo que se ve y lo que no se ve" (5-VIII-1899: s/p).

- En El País firmó en 1899 dos artículos: "Los nombres (a los Pepes)" (20-III-1899: s/p) y "El arte y el obispo o los tapices de Villoldo" (3-IV-1899: s/p).

- En Electra publicó dos artículos: "El jesuita y Jesús" (16-III-1901: 32) y "En el confesionario: Coloquios de Cuaresma" (30-III-1901: 94-96).

- En El Quijote volvió a publicar: "El jesuita y Jesús" (25-X-1901: s/p).

- En Vida Nueva vieron la luz 17 artículos: "La nueva carrera" (17-VII-1898: s/p), "La Iglesia de los ricos" (7-VIII-1898: s/p), "Confundir las especies" (14-VIII-1898: s/p), "Los neos condenados" (21-VIII-1898: s/p), "Los comulgadores" (6-XI-1898: s/p), "Monjas y esclavas" (13-XI-1898: s/p), "Los carlistas y el tormento" (18-XII-1898: s/p), “'Siempre jesuitas! (el padre Mir en la Academia)” (25-XII-1898: s/p), "El arte cristiano agoniza" (8-I-1899: s/p), "Sermón académico" (29-I-1899: s/p), "Los Reyes en el destierro" (29-I-1899: s/p), “Ángeles de caridad" (12-II-1899: s/p), "Los misterios de Madrid: La secretaría episcopal" (5-III-1899: s/p), "La España de la Edad Media" (9-IV-1899: s/p), "Castelar y la Iglesia española" (4-6-1899: s/p), "Opiniones sobre el meeting" (2-7-1899: s/p), "León XIII y los Congresos Católicos" (10-9-1899: s/p).

La atribución del seudónimo Pío Quinto a Baroja se debe, en primera instancia, a Luis Urrutia Salaverri quien en "Baroja y el periodismo" (1967: 655-665) y, sobre todo, en el prólogo del primer volumen de Hojas sueltas (Baroja 1973: 8-35) defendió

Sobre los artículos de Pío Quinto es preciso hacer las siguientes aclaraciones: en la nómina de los textos aparecidos en Vida Nueva se incluyen dos artículos que aparecen firmados con las iniciales "P.Q.": "Confundir las especies" y "Los Reyes en el destierro". "Opiniones sobre el meeting" no es un artículo sino que se trata de una entrevista. Beatriz de Ancos no cita los artículos de Pío Quinto aparecidos en El Motín. Con respecto a "Confundir las especies" afirma que salió el 11 de agosto de 1898 cuando en realidad salió el día 14 (1998: 91). También confunde el título de "Los neos condenados": cambia la palabra "neo" por "reo" (1998: 91). Del artículo "Opiniones sobre el meeting" afirma que fue firmado por Pío Baroja cuando en realidad quien lo firma es Pío Quinto (1998: 91). En las Obras completas no se incluyen los textos aparecidos en El Motín, ni los firmados por "P.Q.", ni el texto "Opiniones sobre el meeting". 
tal hipótesis. Las razones que ofrecía eran las siguientes:

- La coincidencia del nombre de pila del autor con el del seudónimo.

- La similitud entre el estilo de Baroja y el de Pío Quinto, por más que no se ofrecieran detalles acerca de en qué consistía tal similitud.

- El hecho de que Pío Quinto escribiera en Electra dos textos en la sección de "Crítica, Religión, Sociología, Política y Actualidad”, de la cual se responsabilizaba Baroja. Baroja, por otro lado, había publicado con su propio nombre otros tres artículos: "Política experimental" (16-III-1901: 9-11), "Domingo en Toledo" (23-III-1901: 5455) y "El amigo Ossorio" (13-IV-1901: 133-136). El escritor vasco se habría servido en esa revista -y en su propia sección- del seudónimo Pío Quinto porque así se lograría dar la impresión de que colaboraban más autores de los que en realidad lo hacían.

Desde entonces la crítica aceptó, con más o menos reparos, la identidad barojiana de esa firma. María del Pilar Celma Valero, en su catalogación de las revistas del fin de siglo, creía razonable tal hipótesis (1991: 45), y Beatriz de Ancos, en su estudio sobre el Baroja periodista, la consideraba "bastante aceptable" (1998: 50). Las dos autoras, sin embargo, expresaban ciertas reservas.

José Carlos Mainer y Juan Carlos Ara Torralba, encargados de la reciente edición de las Obras completas de Pío Baroja, incluyen en ellas los textos de Pío Quinto y con ello "canonizan" su autenticidad barojiana. Añaden esta explicación:

Al seguidor del Baroja más impío, más ‘joven bárbaro', le han de gustar sin duda alguna muchos de estos artículos sotanófobos, especialmente los que en Vida Nueva firmó como 'Pedro Recio de Tirteafuera' o 'Pío Quinto' -quien dude de la autoría de Baroja, que observe la frase '¡Ah, las formas! Son el todo' de 'La nueva carrera' (Vida Nueva, 17-VII-1898), coincidente con el rótulo 'La forma es todo' (El Globo, 17-X-1898)- aquí recuperados (Baroja 1999: 17-18).

Vistos en su conjunto, los argumentos expuestos son razonables pero no definitivos. En el caso de Urrutia Salaverri, la coincidencia de los nombres de pila y la presunta analogía de estilo no resultan demostrativas en sí mismas. La estrategia de firmar con dos nombres distintos en Electra es verosímil, pero tampoco se trata de una prueba categórica: es cierto que otros autores -véase el caso de Dionisio Pérez en Vida Nueva- habían tenido comportamientos análogos, pero otros muchos en esa misma situación -José Nakens, por ejemplo, en El Motín- no lo habían hecho. Lo expuesto en las Obras completas de Baroja, como se verá a continuación, tampoco es palmario: el hecho de que Pío Quinto y Pío Baroja coincidieran, con pocos meses de diferencia, en el uso de la expresión "la forma es todo", podría ser concluyente si se tratara de una manera de decir peculiar, pero resulta que ésa era una locución común que bien pudiera aparecer repetida por casualidad. Sin ir más lejos, por ejemplo, en Madrid Cómico reproducen -también en 1898- el "Atrio" que Jacinto Benavente había escrito para la edición de El Poema del Trabajo de Martínez Sierra; allí se lee: "Templo del Arte consagrado a la Belleza, deidad misteriosa, impenetrable en su esencia; porque en ella la forma es todo" (24-XII-1898: 883). La coincidencia en esa expresión no sería tampoco una razón determinante. 


\section{Pío Quinto, un autor anticlerical}

La mejor manera de echar luz sobre la autoría de estos textos consiste en su análisis aislado. Leídos en su conjunto, los artículos firmados por Pío Quinto presentan una excepcional unidad de contenido anticlerical. La ironía que se contiene en la propia adopción del seudónimo apunta en esa dirección: el Papa Pío V fue, además de Gran Inquisidor, un luchador en la implantación de la ortodoxia católica y en la aplicación de las directrices del Concilio de Trento.

En los artículos de Pío Quinto se hace hincapié en desvelar lo que podrían denominarse las malas artes de la Compañía de Jesús, con especial atención a la “Congregación de los Luises", una organización católica inspirada por jesuitas (López 1999: 1-50). En "La nueva carrera", por ejemplo, se desvela cómo abandonarse en las manos de un padre jesuita e ingresar en ella era un seguro de riqueza, poder e impunidad jurídica. El artículo estaba escrito en forma de diálogo y uno de los que interviene se resiste a ello:

Basta (...) no quiero saber más. Veo que sois unos fantoches movidos por gente que no conocéis y que os desprecia; que vivís en continuo espionaje, en escepticismo enervante y en atonía moral desastrosa. Hampa enguantada y podrida, siervos mercenarios, tentáculos de un pólipo inmenso que os adherís o hacéis el vacío, allí donde os mandan; organización anticristiana de un falso cristianismo, y milicia cuyas armas son el descrédito y la perfidia (...) así profanan lo más santo, lo más vigoroso y fresco de la raza, la esperanza de los pueblos, la juventud, que matan en flor secando su rica savia (17-VII-1898: s/p).

Pío Quinto muestra una extraordinaria familiaridad con el día a día eclesiástico madrileño. Conoce, con nombres y apellidos, cuáles son las personas que se encuentran en ese circuito social de la Compañía de Jesús. El lector de "Los comulgadores" (6XI-1898: s/p), por ejemplo, se entera de que en la Iglesia de la Flor Baja aparecen siempre las mismas caras en las celebraciones litúrgicas, se entera también de que el padre Sanz estafó a una marquesa, de que el padre Hidalgo es el encargado de lo que él llama "los comulgadores", y de que el padre Garzón dirige la sociedad de las "madres cristianas".

Es, además, el "especialista" en materia religiosa del semanario Vida Nueva: a él se le encarga la crítica de textos religiosos (9-IV-1899: s/p). Cuando tenga que hablar sobre un suceso, lo interpretará en relación con la religión: así, por ejemplo, al morir Castelar, Pío Quinto firmará "Castelar y la Iglesia Española" (4-VI-1899: s/p). Y cuando le entrevisten y soliciten su opinión acerca del meeting de Montjuich, un suceso político, él dirá:

Para meeting español, y celebrado bajo el poder de Poncio Silvela, no estuvo mal, aunque sobró allí mucha filosofía y mucha jurisprudencia. Todo lo di por bien empleado al ver cómo tenían que componer su cara los conocidos personajes adictos a la Compañía de Jesús y comprometidos con el clericalismo a cada explosión de odio contra los jesuitas y la reacción radical (2-VII-1899: s/p).

Como experto en cuestiones religiosas de Vida Nueva, a él acudirán para que aclare qué significan las condenas que los diversos obispos hacen a la revista. Él tendrá que salir al paso para explicar, con argumentos teológicos, que la publicación 
no está excomulgada (14-VIII-1898: s/p). A él acuden para que aclare qué es un Congreso Católico y qué papel tiene el Papa León XIII en él (10-IX-1899: s/p).

Los textos de Pío Quinto nos sitúan ante un escritor ducho en la menudencia y el día a día de los círculos de católicos ignacianos, circunstancia vital que parece más bien ajena a Baroja. Baroja podría haber decidido adoptar otro nombre para escribir artículos muy anticlericales y antijesuíticos pero no parece ése el talante ni la formación del joven médico. No se encuentra nada parecido en lo que publica en esos mismos años en Revista Nueva o en El País. Es difícil creer, además, que si Baroja hubiera tenido la oportunidad de publicar en revistas del renombre de Vida Nueva lo hubiera hecho sólo con colaboraciones de esta clase y evitando que lo identificaran. Así, pues, las razones contrarias a la identificación de Baroja con Pío Quinto parecen, como mínimo, tan fuertes como las favorables.

\section{LA PRENSA CLERICAL}

El carácter anticlerical de Pío Quinto es precisamente el que permitirá encontrar pistas sobre su posible identidad. La prensa católica, muy combativa en esos años, se cansó de sus invectivas y se centró en tratar de desenmascararlo. La revista que dedicó más esfuerzos fue La Lectura Dominical (1894-1936), cabecera que ejercía de portavoz del Apostolado de la Prensa. Se trataba de una publicación que en los años del fin de siglo tiraba más de diez mil ejemplares. En el periodo de un mes -entre septiembre y octubre de 1898-Minimus, uno de sus colaboradores habituales, escribe dos artículos contra Pío Quinto.

En uno de ellos, aparecido el 2 de octubre de 1898, Minimus sale en defensa del Arzobispo de Valencia. Había aparecido en El Nacional un artículo donde se acusaba a este prelado de haber hecho un nombramiento contra el sentido común y contra los deseos de Roma. Minimus ataca al autor de ese artículo:

El Juan Mariposa, el Pío Quinto, el... el clérigo ese corrompido, hereje y embustero, dijo en uno de sus periódicos algo ofensivo contra el Sr. Herreros, Arzobispo de Valencia, a propósito de un nombramiento (...). Como el actual fiscal de la Rota, siendo Vicario general de esta diócesis, no tuvo más remedio que sentarle las costuras al cleriguillo, de quien se supo con testimonio irrecusable, que era autor de ciertos libros aborrecibles, cuyo inspirador no podía ser otro que el mismo Satanás, no pierde ahora ocasión el ex-sacristán de San Ginés de tomar ruin venganza de lo que él juzga persecución y no es sino justicia seca. (...) Esa víbora que en Vida Nueva, en El País, en El Nacional y dondequiera que pueda colarse, deposita el jugo ponzoñoso de su pluma, ¿continuará manchando impunemente reputaciones, difundiendo mentiras, haciendo alarde de conocimientos que no posee, sino a medias y como quien no ha hecho más que leer libros aprisa y corriendo, y escandalizando a todo el que de cerca o de lejos tiene la desgracia de saber que vive? ¿No sería conveniente prohibir todo periódico donde él escribiera con cualquier pseudónimo, ya que tan fácilmente se le conoce por sus perfidias? (2-X-1898: 639).

Minimus sostiene que el seudónimo Pío Quinto pertenecía a un clérigo que también firmaba como Juan Mariposa; se trataba de un sacerdote que habría ejercido en la parroquia de San Ginés y que, a causa de ciertos libros, habría sido apartado de su ministerio clerical. Aunque las pistas que ofrece ya son claras para aventurar 
una identidad, en el segundo texto ofrece los datos suficientes para determinarla sin duda alguna. En esta ocasión se trata de la contestación a "Confundir las especies" (14-VIII-1898: s/p), un texto publicado por Pío Quinto en Vida Nueva en donde se respondía a la carta pastoral que el arzobispo de Sevilla había dirigido a los fieles de su diócesis. En ella el prelado daba "la voz de alerta para que no lean ni dejen leer a los suyos la revista Vida Nueva" (Blasco 14-VIII-1898: s/p). Se difundió el rumor de que Vida Nueva había sido excomulgada y Pío Quinto salió al paso con ese artículo. Allí explicaba que:

Las excomuniones se fulminan contra los pertinaces en la herejía, después de amonestados en forma más de una vez y por la autoridad del superior legítimo, que es el obispo de la diócesis donde se publica lo que es objeto de esa censura (...). No nos asombra nada de esto, aquí donde casi nadie sabe qué es una excomunión, donde se ignora que los periódicos no pueden ser excomulgados y no se está al tanto de cómo debe ejercerse la censura de los artículos que en cada número pudieran ser objeto de ella (14-VIII-1898: s/p).

Y como respuesta a este artículo, Minimus vuelve a coger la pluma, el 4 de septiembre de 1898, para, entre otras cosas, revelar quién estaba, en su opinión, detrás del seudónimo Pío Quinto:

Pero vamos por partes; que estas cosas de Blasco [Eusebio Blasco, director de Vida Nueva] y de su Vida Nueva o de su Vida Mala, con el aditamento de su cleriguillo a quien ya no le faltaba más que echarse a la vida esa, la de Blasco, hay que tomarlas despacito y por su orden. El golfín eclesiástico, contratado en calidad de santo padre del nuevo órgano de los diablos predicadores, ha querido desvirtuar la prohibición y censura dirigidas por algunos Prelados contra Vida Nueva, trayendo a cuento prohibiciones y censuras de periódicos católicos. (...) Pero lo que no dice ese saltamontes de sacristía es que los periódicos católicos, como todo fiel cristiano, empiezan por someterse inmediatamente a la autoridad legítima que los censure o prohíbe. Y eso no lo ha hecho ni lo hace Vida Nueva ni el ex sacristán de San Ginés, ni el autor de Los secretos de la confesión y El sacramento espúreo, a quien no han podido sujetar trapenses ni paúles, y que sin duda, por eso, nos lo tiene guardado el famoso Eusebio para desempeñar la mitra de Toledo cuando triunfen sus ideales. Y no haciendo eso, hay la misma diferencia entre la prohibición de un periódico católico y la de otro, inspirado por Blasco y embadurnado por el cleriguillo, que la que hay entre un sacerdote pecador, pero arrepentido, y un raposo con sotana, ocupado constantemente en ver cómo engaña a sus superiores para seguir escandalizando con su lenguaje y sus costumbres, mintiendo en conversaciones y periódicos y deshonrando la túnica sagrada que en mal hora vistió y que algún día, si no se arrepiente de veras, le sirva de envoltura en que se abrase su alma para siempre. Y me parece que la diferencia no es menuda; pero váyale a V. a Juan Mariposa, al Devoto Parlante y a Pío Quinto con esas filigranas. Lo que él dirá: no me ha detenido a mí la santidad del confesionario, ipara que yo haga caso de semejantes pequeñeces...! (4-IX-1898: 575).

De acuerdo con las tesis de Minimus, Pío Quinto usaba también el seudónimo Devoto Parlante y era el autor de dos libros: Los secretos de la confesión y El sacramento espúreo. Los libros habían sido escritos por el sacerdote José Ferrándiz y Ruiz. Antes de estudiar la posibilidad de que Ferrándiz fuera Pío Quinto, puede verse otra referencia aparecida unos meses después en el Resumen de Arquitectura. Revista de la Sociedad Central de Arquitectos, una publicación no clerical. Allí se vuelve a 
insinuar que José Ferrándiz era Pío Quinto: se alude a su condición sacerdotal y a los dos arrepentimientos públicos de los que, según se verá, fue protagonista. El artículo era la respuesta a "El arte cristiano agoniza" (s/p), un texto que Pío Quinto había firmado en Vida Nueva. En el artículo del Resumen de Arquitectura se puede leer:

Falta ya espacio para ocuparnos de otros asuntos dignos de llamar la atención; pero aunque tarde, forzoso es ocuparnos de un artículo publicado en Vida Nueva, hace ya tiempo, y firmado por Pío Quinto. Es un desahogo bilioso, en la culta forma modernista, en el que se trata la Arquitectura y los Arquitectos por modo tan desenfadado como falto de conocimiento. (...) Invitaríamos (...) al sabio autor del articulejo a discutir (...), que no sería la primera ni la segunda vez que hubiese confesado el yo pequé en público, quien, aunque se firme con un nombre pontificio, no ha podido pasar de una categoría mucho más humilde (Lampérez y Romea 1-III-1899: 33).

\section{El Clérigo José Ferrándiz y RuIZ}

Con lo dicho hasta ahora y atendiendo a las posibles revelaciones que desde $L a$ Lectura Dominical se hicieron, parece conveniente profundizar en la figura de José Ferrándiz ${ }^{2}$. Los aspectos mencionados más arriba son sólo una pequeña muestra de la azarosa vida de este sacerdote. Ferrándiz fue un personaje tan célebre durante los años del fin de siglo - el "famoso cura Ferrándiz” lo llamará Caro Baroja (1980: 220)-, como desatendido después -"caído en el más oscuro de los olvidos- (Molina 1998: 295). Sus idas y venidas llenaron números enteros de periódicos hasta constituirse, durante años, en un ejemplo de cierta resistencia anticlerical:

Porque Ferrándiz, fuera del valor personal, era un haz de concentración de muchas simpatías, el foco de muchas admiraciones, el fijador de muchas creencias, el eje de muchas convicciones, así en España como fuera de ella. Cualquiera que sea la estructura que supongamos en el anticlericalismo español, al buscar su columna vertebral, no podrá construirse sin señalar en ella a Ferrándiz como una de sus principales vértebras (Anónimo 16-XII-1915: 3).

Ferrándiz nació en Lorca, provincia de Murcia, en 1852, en una familia humilde. A los pocos años quedó huérfano de padre - que pintor-, y como consecuencia "conoció desde niño los sinsabores de la miseria, lo que hubo de influir en varias ocasiones en su vida" (Anónimo 1924: s/p). Recibió la formación básica en un colegio de Escolapios. Cuando contaba pocos años se trasladó a la capital con su madre -en 1869 ya vivían en Madrid (Molina 1998: 303)-. Quiso ser clérigo y se formó como "seminarista externo", lo cual suponía hacer los estudios eclesiásticos sin acudir al seminario, y suponía generalmente también que sólo podía aspirar a una parroquia rural o a una sencilla capellanía. Tras su ordenación, en torno a 1877, estuvo unos años en Llerena (Badajoz) y de allí regresó a Madrid, a la parroquia de San Ginés, en cuyos archivos aparece entre 1888 y 1900 (aunque es probable que llegara al menos un par de años antes).

La bibliografía acerca de Ferrándiz es muy escasa. Sobre su compleja personalidad debe leerse el análisis del profesor Manuel Martínez Arnaldos (1993: 295-302) en el que se toman como base las novelas del clérigo. 
La madre de Ferrándiz - a la que estaba muy unido- enfermó gravemente durante los primeros años de la década de 1880. El cura hubo de buscar dinero para el tratamiento de la enfermedad. Según explicó él mismo, nadie de la órbita eclesiástica se brindó a prestarle ayuda, circunstancia que produjo en él una doble trasformación: se desengañó de la "estructura de la Iglesia" e inició, como fuente de ingresos, una carrera literaria en medios anticlericales. Lo explica en tono apologético una breve biografía aparecida en El País:

El padre Ferrándiz oscuro clérigo de Madrid vivía contento con ser explotado como sus colegas, trabajaba y callaba sin pensar en escribir, sino en leer. Así habían pasado bastantes años de su vida clerical y hubieran pasado todos. Tímido y altivo a la vez, conformábase con la pobreza por no solicitar medros arrastrándose; ya sabía que en la Iglesia no sirve la conducta, ni el trabajo, ni nada y se había resignado. Pero un día enfermó su madre que era su ídolo. Esta señora tenía una obsesión, el hospital. Si he de ir a él, decía, me moriré en la camilla por el camino. Antes que eso, robaré en despoblado si es preciso, le contestaba su hijo. La enfermedad fue larga, el jornal de la Iglesia no bastó a sufragar los gastos, vinieron los apuros y las deudas y entonces el clérigo hizo lo que tanto le repugnaba, pedir, llorar, arrastrarse; todo en vano. Lleve usted a su madre al hospital, le dijeron algunos sacerdotes, tan encopetados como caritativos al negarle todo auxilio, iy no les pedía dinero, sino trabajo! ¡Sublime caridad la de la Iglesia... con los ricos! En un momento de ira, de despecho y desesperación oyó las proposiciones de un conocido suyo periodista, y él, que no se creía ni se cree escritor, escribió a la desesperada violentando sus creencias, hecho héroe por fuerza, y a eso que hizo como el que roba un pan siendo honrado, debió que su madre tuviese médicos, viese las deudas pagadas, y muriese en su cama sin faltarle nada ni aun los sufragios ipagados con dineros de la prensa avanzada! Y una sepultura decente ¡sarcasmo horrible! (Anónimo 11-III-1900: s/p).

Aceptó, pues, un puesto como colaborador, a partir de 1883, en Las Dominicales del Libre Pensamiento, órgano de la masonería, donde firmaba con el seudónimo Constancio Miralta. Entre 1885 y 1887 colaboró con El Resumen, una publicación de la izquierda liberal, firmando como "Un clérigo de esta corte". También publicó en El Progreso y en El Motín. A sus colaboraciones en prensa deben sumársele los libros Memorias de un clérigo pobre (1884), Los secretos de la confesión (1886) y El sacramento espúreo (1887) firmados por Constancio Miralta. También se suele atribuir a Ferrándiz El Papa y los peregrinos (1888), volumen que apareció firmado por Próspero Marsigli y traducido por el P. Biosca.

En pocos años Ferrándiz, oculto tras sus seudónimos, se convirtió en un gran generador de controversia: primero en el mundo del periodismo y, más tarde, en el de los tribunales. Se pueden encontrar reacciones de uno y otro signo en la prensa católica y en la anticlerical. En El Siglo Futuro, por ejemplo, critican una de esas obras:

Con el título de El sacramento espúreo, exposición y crítica severísima del matrimonio canónico, el redactor de El Motín y de Las Dominicales del Libre Pensamiento, Constancio Miralta, que para mayor escarnio se llama presbítero (y desgraciadamente se dice que lo es en efecto) ofrece al pacífico cristiano transeúnte en este brevísimo sumario, todas las herejías, impiedades, sacrilegios y horrores que forman la pornográfica y execrable obra (Anónimo 19-I-1887: s/p). 
Y en La Discusión, sin embargo, las alaban:

Los secretos de la confesión es una crítica acabada y completa, no ya sólo del tema expuesto en su título, sino de los vicios de la sociedad católica y de la organización del clero. (...) Nosotros lo hemos leído con verdadera satisfacción: una vez comenzado no hemos sabido dejarlo de la mano. Desde el punto de vista literario y desde el de la moral universal, el Sr. Miralta ha hecho una buena obra; verdadero ariete contra el fanatismo y las preocupaciones religiosas. Felicitamos cordialísimamente al autor y recomendamos eficacísimamente su libro (Anónimo 23-II-1886: s/p).

Los desencuentros en los tribunales no llegaron hasta que los responsables de la prensa católica no descubrieron quién se escondía detrás de esos seudónimos. El primero de sus litigios comenzó en septiembre de 1886. Damián Isern, director de $L a$ Unión Católica, denuncia que Ferrándiz estaba tras los artículos heréticos firmados por Un clérigo de esta corte en El Resumen. La posibilidad de que un clérigo firmara aquellos textos es razón de que, paralelamente, se iniciara un proceso canónico. Ambas causas fueron muy seguidas por la prensa. En La Iberia, por ejemplo, dan cuenta de un acto de conciliación entre ambos: "En el Juzgado del Congreso se celebró ayer juicio de conciliación entre el director de La Unión, Sr. Isern, y D. José Ferrándiz, a quien se atribuyen los artículos de El Resumen firmados por Un clérigo de esta corte. No ha habido avenencia" (Anónimo 3-IX-1886: s/p). Y en La Época, por su parte, se informa sobre la evolución del proceso canónico: "El juzgado eclesiástico de esta diócesis ha admitido la denuncia canónica presentada contra el presbítero adscrito a la parroquia de San Ginés, D. José Ferrándiz, por el director de La Unión, señor Isern, que ha sido citado para declarar en la causa que se instruye al efecto" (Anónimo 8-IX-1886: s/p).

El resultado fue que Isern retiró la acusación civil porque no podía demostrar fehacientemente la paternidad de tales artículos, mientras que la causa canónica se saldó con catorce meses de inhabilitación ministerial y la conciliación con la Iglesia merced a las conversaciones que Ferrándiz mantuvo con el obispo Ciriaco Sancha. De hecho, si salió prácticamente indemne de estos procesos se debió en buena medida a la labor de este obispo, que pretendió ganar a Ferrándiz a la causa de la ortodoxia. Consideró que obligarle a una retractación pública hubiera supuesto un escándalo y que mejor era dejar las cosas como estaban por más que Ferrándiz fuera, de hecho, culpable. Le obligó a hacer unos ejercicios espirituales con los Paúles, a abandonar las publicaciones anticlericales y a utilizar su indudable talento como escritor para -hacer el bien-, escribiendo artículos sobre arte religioso en la prensa conservadora. En los años siguientes su firma apareció en El Nacional, en El Movimiento Católico, en La Ilustración Católica y en La Unión.

Sobre la vida de Ferrándiz en los años posteriores hay cierta confusión: si bien parece que dejó de escribir en medios anticlericales y que durante un tiempo mantuvo la apariencia de ser un clérigo ortodoxo, también se le acusó de haber tenido un hijo. Y él mismo, de hecho, confesó que "muerta ya mi madre, todo me importaba un bledo" (Molina 1998: 304). La cuestión es que ciertos sectores conservadores no quedaron satisfechos con la retirada de la denuncia civil y el perdón canónico. Y por ello en cuanto vieron oportunidad volvieron a denunciarle por haber escrito los artículos y libros por los que se le había denunciado la primera vez. La denuncia fue posible 
gracias a la aparición de un testigo, José Matarredonda, quien había sido administrador de Las Dominicales del Libre Pensamiento y compañero de andanzas de Ferrándiz. Para unos, Matarredonda denunció "desengañado por lo que entre sectarios vio y tuvo que sufrir, volvió los ojos a la Religión en que había sido educado" (Anónimo 1896: s/p), mientras que para otros "compraron a Matarredonda ofreciéndole una colocación y una suma de dinero, si denunciaba y además entregaba los restos de las ediciones de los folletos del acusado y otros autores" (Anónimo 2-IV-1900: s/p).

Sea como fuere, tras el juicio se condena a Ferrándiz a que se retire a la Trapa de Val de San José, en Getafe, y se le prohíbe publicar nada en la prensa si no es con su nombre y con la conveniente censura eclesiástica. El padre Ferrándiz acepta la pena, al menos inicialmente, y se retira a la Trapa, pero unos meses más tarde, en febrero de 1897, la prensa informa de su fuga. El Boletín Eclesiástico se hace eco de un edicto donde se solicita información sobre su paradero y se condena gravemente a todos aquellos que le brinden ayuda. Aunque, según parece, la fuga no fue sino un retraso, ocasionado por una enfermedad, en el regreso a la Trapa. Este suceso, sin embargo, fue el comienzo de una serie de enfermedades que Ferrándiz encadenó en la Trapa y en una segunda residencia a la que fue destinado para recuperarse. Por miedo a enloquecer, huyó definitivamente y se declaró en rebeldía. Se trasladó a un piso de la calle Fuencarral y allí se quedó al margen de la Iglesia y subsistiendo con sus artículos de prensa.

Ésta es la situación en la que se encontraba Ferrándiz durante los meses que firmó artículos Pío Quinto. Las apariciones públicas y los escritos de Ferrándiz desde entonces $-\mathrm{y}$ hasta su segunda y definitiva conversión- fueron numerosas. Su estudio excede el propósito de estas páginas y no arroja luz sobre la cuestión que ahora se plantea. La cuestión es que permanecerá en estado de rebeldía hasta su arrepentimiento definitivo en 1915, fecha en que firma la siguiente retractación:

In Nomine Iesu. Yo, el abajo firmante, presbítero, profundamente arrepentido, declaro que, cegado por humanas pasiones durante no pocos años, en dos etapas distintas, he sustentado en el libro y en la prensa errores y extravíos contra la fe cristiana, con irrisiones y blasfemias de lo más sagrado, y ataques a la autoridad de la Iglesia. Contiénese todo esto en los libros titulados: Memorias de un clérigo pobre, Secretos de la confesión, Sacramento espurio, El Papa y los peregrinos, Memorias de una monja, Das heutige Spanien unter dem joch des papstums [La España bajo el poder pontificio, en alemán y sólo publicado en Alemania, Francfort], Sotanas conocidas. En la prensa, los artículos insertos en Las Dominicales, El Resumen, Vida Nueva, El País, El Progreso [Madrid-Barcelona], El Motín, El Radical, y algún otro. Ahora, deplorando con toda mi alma tamaños extravíos, afirmo pública y solemnemente que abjuro de cuanto contiene esta obra desdichada contraria al dogma, a la moral, a la Historia y a la disciplina de la Santa Iglesia Católica, a cuyo juicio absoluto me someto, hondamente contrito de mis gravísimas faltas, de cuanto haya podido ofender, lastimar o escandalizar a las personas de los prelados, sacerdotes, religiosos y fieles, cuyo perdón cristianamente les pido y de todos espero. Es mi deseo volver a la comunión y obediencia de la Iglesia Católica, nuestra Madre, cuya santa fe confieso y reclamo. En testimonio de lo cual, suscribo y firmo la presente retractación en Madrid a 24 de noviembre del año del señor 1915 (16-XII-1915: 1-2).

El padre Ferrándiz ejerció desde entonces su ministerio en la parroquia de San José de Madrid, donde murió en 1927, en el más absoluto de los olvidos. 


\section{El Seudónimo Pío Quinto}

Sobre la paternidad de los textos de Pío Quinto no se puede ser categórico, aunque lo cierto es que todo apunta a que, por las siguientes razones, fue José Ferrandiz quien los escribió:

- La prensa conservadora, según se vio en los textos de Minimus, le ataca a él por ser su autor. Es cierto que en algunas ocasiones esa prensa le atribuyó textos que no eran suyos, pero también es cierto que la mayoría de los textos que le atribuían sí lo eran. Adicionalmente, se ha visto lo difícil que era demostrar quién se encontraba detrás de los seudónimos.

- Los años de la actividad de Vida Nueva coinciden con los años en los que Ferrándiz está en plena "actividad anticlerical". Dependía económicamente de lo que escribía y, por tanto, debía prodigarse.

- El contenido de los artículos se corresponde perfectamente con el resto de escritos y con la personalidad de Ferrándiz. En uno de ellos hace gala, por ejemplo, de uno de los temas biográficos que más repetía por aquellos años: se quejaba de que le habían forzado (por no ayudarle durante la muerte de su madre y por reabrir el segundo proceso) a quedarse al margen: "A pesar de eso, mi buena fe, imparcialidad o lo que sea, si yo puedo tener algo bueno, que no debo poder ni me han dejado que pueda, ni quiero tampoco tenerlo, contento con ser malo, malísimo y con que me horripilen los buenos" (Pío Quinto 9-IV-1899: s/p).

Pío Quinto coincide también con el padre Ferrándiz en el conocimiento exhaustivo de las menudencias eclesiásticas de la diócesis de Madrid (17-VII-1898: s/p), en la obsesión por demonizar al cardenal Rampolla (21-VIII-1898: s/p), en el conocimiento en primera persona de lo que supone estar -o no estar- excomulgado (14-VIII-1898: $\mathrm{s} / \mathrm{p}$ ), y en la costumbre de escribir sobre historia del arte y sobre historia en general (8-I-1899: s/p).

- En sus retractaciones de 1915 él atestigua haber escrito en Vida Nueva, pero con su firma no aparece ningún artículo en esa revista, ni aparecen escritos con ninguno de los otros seudónimos de Ferrándiz. Se habría servido para publicar en esta revista -según explica Molina- de dos seudónimos: El capellán verdades y Pío Quinto (1998: 317). El seudónimo El capellán verdades sólo aparece una vez en Vida Nueva firmando el artículo "El Obispo de Sión y el clero castrense" (23-IV-1899: s/p), texto que, por el contenido, bien podría haber sido escrito por él. Pero sería muy extraño que Ferrándiz se arrepintiera en sus retractaciones de lo escrito en Vida Nueva si sólo hubiera escrito un artículo, máxime cuando sabemos que colaboró en otras muchas publicaciones a las que ni alude en su retractación por tratarse de colaboraciones pequeñas. Lo lógico es que su colaboración en esta revista fuera notable, tanto como lo fue la de Pío Quinto. No hay, por otra parte, ningún otro seudónimo en Vida Nueva cuya identidad desconozcamos y cuyas colaboraciones fueran significativas como para poder retractarse.

Todo parece indicar, pues, que los artículos que se le atribuían a Pío Baroja bajo el seudónimo Pío Quinto fueron escritos en realidad por el clérigo José Ferrándiz. 


\section{OBRAS CITADAS}

Anónimo. 23-II-1886. "Bibliografía". La Discusión: s/p. . 3-IX-1886. "Tribunales". La Iberia: s/p. 8-IX-1886. "Noticias generales". La Época: s/p. 19-I-1887. "Quos Deus vult perdere”. El Siglo Futuro: s/p. 1896. Boletín Eclesiástico 101: s/p. 20-I-1900. "Ferrándiz y Nocedal (Entrevista con el P. Ferrándiz)". El Pais: s/p. 11-III-1900. "Persecución eclesiástica (el proceso del Padre Ferrándiz)". El Pais: s/p. 18-III-1900. "Sentencia estupenda". El País: s/p. 23-III-1900. "Proceso escandaloso". El Pais: s/p. 2-IV-1900. "Cohecho sagrado". El Pais: s/p. 16-XII-1915. "El Padre Ferrándiz". El Motín 50: 1-2. 16-XII-1915. "La conversión del Sr. Ferrándiz". El Motín 50: p. 3. 1924. Voz “José Ferrándiz”. Enciclopedia Espasa. Madrid: Espasa. Tomo 23, p. 889.

Baroja, Pío. 16-III-1901. "Política experimental". Electra 1: 9-11. 23-III-1901. "Domingo en Toledo". Electra 2: 54-55. 13-IV-1901. "El amigo Ossorio". Electra 5: 133-136. 1973. Hojas sueltas. Madrid: Caro Raggio.

1999. Obras completas: Obra dispersa y epistolario. Vol. 16. Barcelona: Círculo de Lectores.

Benavente, Jacinto. 24-XII-1898. "El poema del trabajo". Madrid Cómico 827: p. 883.

Blasco, Eusebio. 14-VIII-1898. "Al Sr. Arzobispo de Sevilla". Vida Nueva 10: s/p.

Caro Baroja, Julio. 1980. Introducción a una historia contemporánea del anticlericalismo español. Madrid: Editorial Istmo.

Celma Valero, María del Pilar. 1991. Literatura y periodismo en las revistas del fin de siglo: Estudio e indices (1888-1907). Madrid: Editorial Júcar.

De Ancos Morales, Beatriz. 1998. Pio Baroja: Literatura y periodismo en su obra. Madrid: Fundación Universitaria Española.

De Paz, Abdón. 1898. La España de la Edad Media [estudio crítico histórico]. Madrid: Librería de Fernando Fe.

Lampérez y Romea, Vicente. 1-III-1899. "Crónica”. Resumen de Arquitectura. Revista de la Sociedad Central de Arquitectos 3: 30-33.

López Pego s.j., Carlos. 1999. La congregación de "Los Luises" de Madrid. Bilbao: Desclée de Brower.

Martínez Arnaldos, Manuel. 1993. "Anticlericalismo y ficción autobiográfica”. En Romera, José et al. (Eds.), Escritura Autobiográfica: Actas del II Seminario Internacional del Instituto de Semiótica Literaria y Teatral. Madrid: Visor. 295-302.

Minimus (seud.). 4-IX-1898. "Sección de polémica. Fuego graneado". La Lectura Dominical 244: p. 575.

.2-X-1898. "Sección de polémica. Fuego graneado". La Lectura Dominical 248: p. 639.

Miralta, Constancio (seud. de José Ferrándiz y Ruiz). 1884. Memorias de un clérigo pobre. Madrid: Editorial Las Dominicales del Libre Pensamiento. . 1886. Los secretos de la confesión: Revelaciones, misterios, crimenes, horrores y monstruosidades, sacrilegios... y otros excesos o pecados oidos a los penitentes durante larga práctica del confesonario. Madrid: Imprenta de Alfredo Alonso.

1887. El sacramento espúreo: Exposición histórica y crítica del matrimonio canónico. Madrid: Imprenta de Ramón Angulo.

Molina, José Luis. 1998. Anticlericalismo y literatura en el siglo XIX. Murcia: Editorial Universidad de Murcia.

Quinto, Pío (seud.). 17-VII-1898. "La nueva carrera”. Vida Nueva 6: s/p. 
7-VIII-1898. "La Iglesia de los ricos". Vida Nueva 9: s/p. 14-VIII-1898. "Confundir las especies". Vida Nueva 10: s/p. 21-VIII-1898. "Los neos condenados". Vida Nueva 11: s/p. 6-XI-1898. "Los comulgadores". Vida Nueva 22: s/p. 13-XI-1898. "Monjas y esclavas". Vida Nueva 23: s/p. 18-XII-1898. "Los carlistas y el tormento". Vida Nueva 28: s/p. 25-XII-1898. “ ¡Siempre jesuitas! (el padre Mir en la Academia)”. Vida Nueva 29: s/p. 8-I-1899. "El arte cristiano agoniza". Vida Nueva 31: s/p. 29-I-1899. "Sermón académico". Vida Nueva 34: s/p. 29-I-1899. "Los Reyes en el destierro". Vida Nueva 34: s/p. 1-II-1899. "La casa de Pastrana”. El Motín: s/p. 12-II-1899. "Ángeles de caridad". Vida Nueva 36: s/p. 5-III-1899. "Los misterios de Madrid: La secretaría episcopal". Vida Nueva 39: s/p. 20-III-1899. "Los nombres (a los Pepes)". El País 4271: s/p. 3-IV-1899. "El arte y el obispo o los tapices de Villoldo". El País 4285: s/p. 9-IV-1899. "La España de la Edad Media". Vida Nueva 44: s/p. 4-VI-1899. "Castelar y la Iglesia española”. Vida Nueva 52: s/p. 2-VII-1899. "Opiniones sobre el meeting". Vida Nueva 56: s/p. 5-VIII-1899. "Lo que se ve y lo que no se ve". El Motín 26: s/p. 10-IX-1899. "León XIII y los Congresos Católicos". Vida Nueva 66: s/p. 16-III-1901. "El jesuita y Jesús". Electra 1: p. 32. 30-III-1901. "En el confesionario: Coloquios de Cuaresma". Electra 3: 94-96. 25-X-1901. "El jesuita y Jesús". El Quijote 4: s/p.

Urrutia Salaverri, Luis. 1967. "Baroja y el periodismo". En Polussen, Norbert y Jaime Sánchez Romeralo (Coords.), Actas del Segundo Congreso Internacional de Hispanistas. Nimega: Editorial Nimega. 655-665.

Verdades, el Capellán (seud.). 23-IV-1899. "El Obispo de Sión y el clero castrense”. Vida Nueva 46: s/p. 
